\title{
Plant secondary metabolites as defenses, regulators and primary metabolites- The blurred functional trichotomy
}

Matthias Erb ${ }^{a, 1,2}$ and Daniel J. Kliebenstein ${ }^{\mathrm{b}, 1}$

a Institute of Plant Sciences, University of Bern, 3013 Bern, Switzerland

b Department of Plant Sciences, University of California, Davis, CA, USA

ORCID-IDs: 0000-0002-4446-9834; 0000-0001-5759-3175

1 This work was supported by the University of Bern, the Swiss National Science Foundation Grant Nr. 155781 to ME, the European Research Council under the European Union's Horizon 2020 Research and Innovation Program Grant ERC-2016STG 714239 to ME, the USA NSF award IOS 1655810 and MCB 1906486 to DJK, the USDA National Institute of Food and Agriculture the Hatch project number CA-D-PLS7033-H to DJK and by the Danish National Research Foundation (DNRF99) grant to DJK.

${ }^{2}$ Author for contact: matthias.erb@ips.unibe.ch

\section{Abstract}

The plant kingdom produces hundreds of thousands of small molecular weight organic compounds. Based on their assumed functions, the research community has classified them into three overarching groups: primary metabolites which are directly required for plant growth, secondary (or specialized) metabolites which mediate plant-environment interactions and hormones which regulate organismal processes, including metabolism. For decades, this functional trichotomy has shaped theory and experimentation in plant biology. However, evidence is accumulating that the boundaries between the different types of metabolites are blurred. An increasing number of mechanistic studies demonstrate that secondary metabolites are multifunctional and can act as potent regulators of plant growth and defense. Secondary metabolites are also re-integrated into primary metabolism, thus behaving like primary metabolites sensu lato. Several adaptive scenarios may have favored this functional diversity for secondary metabolites, including signaling robustness and costeffective storage and recycling. Secondary metabolite multi-functionality can provide new explanations for ontogenetic patterns of defense production and can refine our understanding of plant-herbivore interactions, in particular by accounting for the discovery that adapted herbivores misuse plant secondary metabolites for multiple purposes, some of which mirror their functions in plants. In conclusion, recent work unveils the limits of our current classification system for plant metabolites and suggests that viewing them as integrated components of metabolic networks that are dynamically shaped by environmental selection pressures and transcend multiple trophic levels can improve our understanding of plant metabolism and plantenvironment interactions. 
Advances Box

- Genetic and chemical experiments demonstrate that plant secondary metabolites can act as regulators of development, growth and defense.

- Secondary metabolites can be re-integrated into plant primary metabolism, thus acting as primary metabolites sensu lato.

- Many secondary metabolites have multiple functions, and these functions are reflected in corresponding spatiotemporal and stress-dependent accumulation and decoration patterns.

- The multifunctionality and metabolic integration of secondary metabolites is mirrored in the adaptations of specialized herbivores.

\section{Introduction}

Plants can use simple, inorganic precursors to synthesize a large diversity of low molecular weight organic compounds. This synthetic capacity helps plants to colonize diverse and challenging environments. Low molecular weight organic compounds are commonly separated by perspective function into primary metabolites, secondary metabolites (also called specialized metabolites) and plant hormones (Figure 1) (Taiz et al., 2015). Primary metabolites are highly conserved and directly required for the growth and development of plants (Fernie and Pichersky, 2015). Secondary metabolites are often lineage-specific and aid plants to interact with the biotic and abiotic environment (Hartmann, 2007). And plant hormones are defined as small compounds that regulate organismal processes, including the production of the other metabolites, by interacting with receptor proteins (Davies, 2004).

The distinction between primary metabolites, secondary metabolites and plant hormones has found its way into textbooks and shapes our thinking in plant biology to this day. An Illustrative example is the field of plant-herbivore interactions, where major efforts have gone into disentangling how plants protect their primary metabolites (serving as nutrients for herbivores) using secondary metabolites (serving as defenses 
for plants), and how adapted herbivores manage to extract primary metabolites while avoiding the negative effects of secondary metabolites (Awmack and Leather, 2002; Howe and Jander, 2008; Zhou et al., 2015; Erb and Reymond, 2019). In this context, plant hormones are investigated as regulators of primary and secondary metabolism, defense and resistance that may be manipulated by adapted herbivores (Howe and Jander, 2008; Schuman and Baldwin, 2016; Stahl et al., 2018), similar to pathogens (Kazan and Lyons, 2014). The biochemical co-evolutionary arms race theory (Ehrlich and Raven, 1964), a key concept in plant-herbivore interactions (Berenbaum and Zangerl, 2008; Jander, 2018), postulates that plant secondary metabolites evolve in response to herbivore pressure, resulting in the evolution of resistance mechanisms in herbivores. The resulting arms race is thought to drive the diversity of plant secondary metabolites and insect herbivores (Futuyma and Agrawal, 2009).

Over the last decades, the distinction between primary metabolites, secondary metabolites and plant hormones has proven a useful approximation. However, the emergence of a more detailed understanding of plant metabolism may require us to revisit this functional partitioning (Neilson et al., 2013; Maag et al., 2015; Kliebenstein, 2018; Pichersky and Raguso, 2018; Zhou et al., 2018). In particular, an increasing number of genetic and functional studies on plant secondary metabolites are blurring the functional trichotomy by showing that plant secondary metabolites can have regulatory functions and serve as precursors for primary metabolites. In this review, we discuss this evidence, mostly focusing on examples that rely on the use of natural knockout variants, mutants and transgenic plants altered in their capacity to produce certain secondary metabolites in combination with chemical complementation assays to demonstrate activity of the metabolites. We illustrate that for an increasing number of plant secondary metabolites, a strict functional separation from regulators and primary metabolites may not do them justice and possibly hinders our progress in understanding their roles for plant survival in hostile environments.

\section{Integration of plant secondary metabolites into regulation and metabolism}

\section{Early evidence for metabolic integration of secondary metabolites}

In 1977, David Rhoades studied the properties of leaf resin of creosotebush (Larrea spp.). He found that the resin, which contained high levels of phenolic acids, absorbed UV radiation, reduced evaporative water loss across cellulose membranes and had the capacity to form complexes with proteins, thus possibly reducing the digestibility of plant materials for herbivores (Rhoades, 1977). Rhoades thus postulated that "... any chemical system possessed by a plant must necessarily be integrated into the total metabolic scheme and multiple functions are to be expected." In other words, Rhoades proposed that secondary metabolites are not endpoints, but integrated components of plant metabolism, and, may by consequence, take on any number of functions, similar to other plant metabolites. Indeed, evidence was emerging at that time that secondary metabolites may regulate growth and defense, as exogenously applied flavonoids could modulate polar auxin transport and catabolism (Stenlid, 1963; Stenlid, 1976), glucosinolate breakdown products could replace auxins in inducing hypocotyl bending (Hasegawa et al., 1986) and induced volatiles promoted resistance and defense regulation in neighboring trees (Baldwin and Schultz, 1983; Rhoades, 1983). 


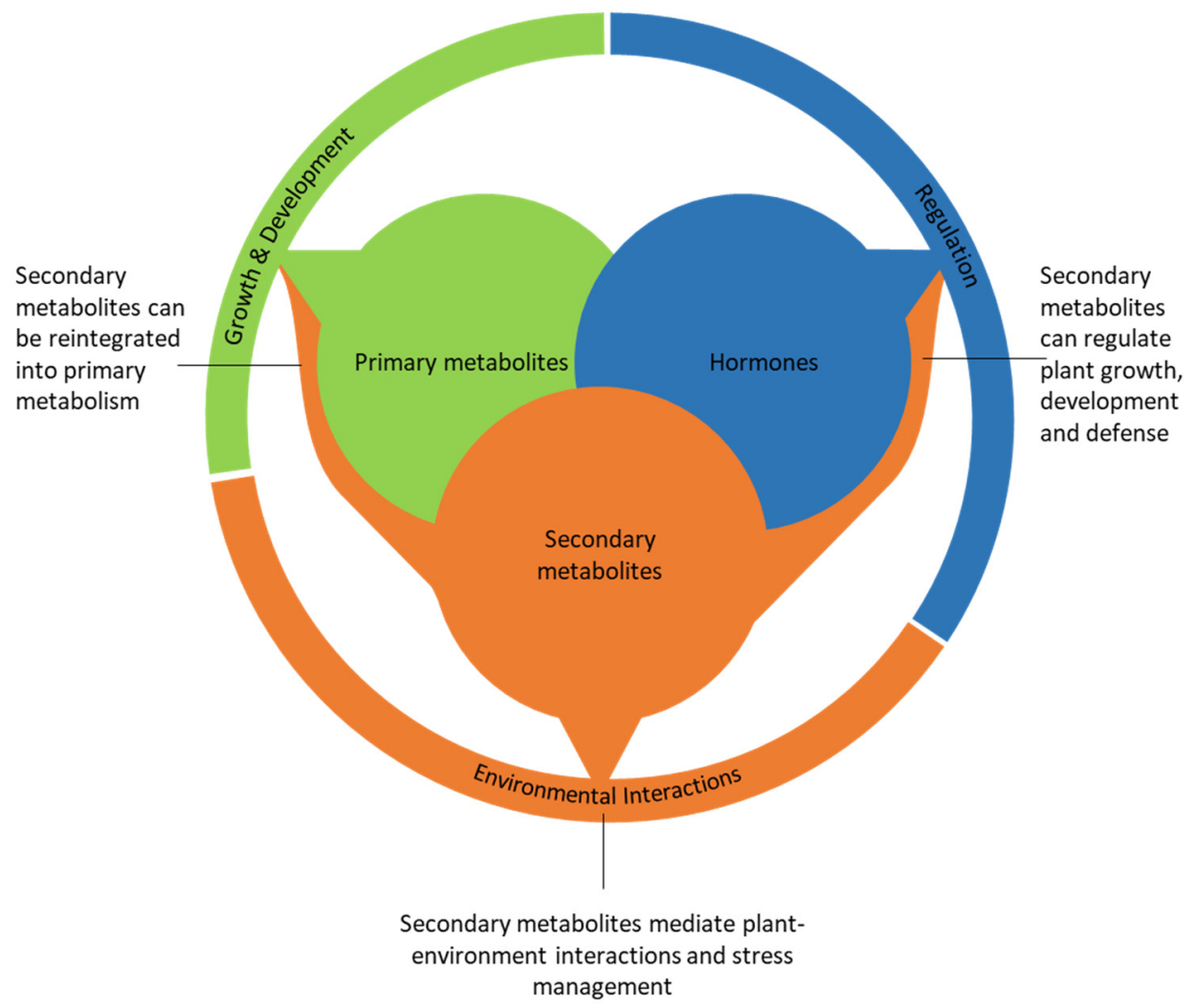

management

Figure 1. Small molecular weight compounds in plants are functionally classified as primary metabolites, secondary metabolites or hormones. Current work on plant secondary metabolites demonstrates that many of them also have regulatory roles, and some are demonstrated precursors of primary metabolites. Note that primary metabolites and hormones also show functional overlap with the other metabolite classes (not discussed here). These findings blur the functional trichotomy of plant metabolism and call for a reassessment of ecological and evolutionary frameworks that are based on this model.

\section{Secondary metabolites as regulators of plant defense}

Following early preliminary evidence of secondary metabolites regulating defenses, genetic evidence followed in 2009, when it was reported that Arabidopsis thaliana mutants defective in indole glucosinolate biosynthesis no longer mount a callose defense response following Flg22 treatment. Callose formation is rescued by adding 4-methoxy-indol-3-ylmethylglucosinolate (Clay et al., 2009). The myrosinase PEN2 is required for this phenomenon, implicating glucosinolate breakdown in callose regulation (Clay et al., 2009). Shortly thereafter, it was discovered that indole-derived benzoxazinoid secondary metabolites have a comparable callose regulatory function in cereals. Benzoxazinoid-deficient $b \times 1$ maize mutants are defective in aphid- and chitosan-induced callose deposition and callose induction is rescued by the addition of DIMBOA or DIMBOA-Glc (Ahmad et al., 2011; Meihls et al., 2013). In both cases, the capacity to regulate callose is structurally specific and depends on the modification of the indole-derived ring. In Arabidopsis, indol-3-ylmethylglucosinolate, which lacks a methylated hydroxy-group on the aromatic ring is inactive, while the methylated form is active (Clay et al., 2009). In maize DIMBOA-Glc, which lacks a methylated hydroxygroup at the nitrogen is active, while the methylated form (HDMBOA-Glc) is inactive ( $\mathrm{Li}$ et al., 2018a). While the callose response to benzoxazinoids is conserved between wheat and maize, they do not elicit callose in Arabidopsis, and intact glucosinolates do not elicit callose in maize ( $\mathrm{Li}$ et al., 2018a). These studies show that callose regulation 
by secondary metabolites is highly specific, tightly controlled and likely evolved 154 repeatedly. The mechanism underlying secondary metabolite-induced callose formation awaits to be elucidated. Glucosinolates and benzoxazinoids may for instance promote callose production by regulating hormonal pathways (Burow et al., 2015; Katz et al., 2015), through transcriptional regulation (Kim et al., 2015), or by directly initiating callose formation post-translationally.

Interestingly, glucosinolates and benzoxazinoids also seem to regulate the accumulation of other secondary metabolites (Hemm et al., 2003; Kim et al., 2015; Li et al., 2018a). In Arabidopsis, mutants defective in the CYP83B1 enzyme required for indole glucosinolate production also show lower accumulation of the phenylpropanoid sinapoylmalate (Kim et al., 2015). The phenylpropanoid phenotype is rescued in mutants that no longer produce the substrate of CYP83B1, indole-3-acetaldoxime (Kim et al., 2015), suggesting that it may be the aldoxime overaccumulation rather than the lack of downstream glucosinolates that suppresses sinapoylmalate. Suppressor screens showed that the phenylpropanoid phenotype is also absent in plants that have mutated $M E D a / b$ genes encoding key components of a large multisubunit transcriptional complex that regulates phenylpropanoid biosynthetic genes (Kim et al., 2015; Dolan et al., 2017). A recent study demonstrates that a group of Kelch Domain F-Box (KFB) genes that are involved in PAL inactivation (Zhang et al., 2013) are upregulated in indole glucosinolate mutants in a MED5-dependent manner, while PALactivity is suppressed (Kim et al., 2020). PAL-activity and sinapoylmalate accumulation are (partially) rescued in glucosinolate-deficient KBF mutants (Kim et al., 2020). The model emerging from these studies is that aldoximes which accumulate in CYP83B1 mutants increase KFB-mediated PAL degradation through MED5 transcriptional regulation as well as other, yet unknown mechanisms (Kim et al., 2015; Kim et al., 2020). As aldoximes are produced by many different species, this form of defense regulation may also occur beyond glucosinolate-producing plants (Kim et al., 2020). Interestingly, wheat lines overexpressing a maize benzoxazinoid $O$-methyl transferase and thus accumulate more HDMBOA-Glc and less DIMBOA-Glc also show higher levels of the phenylpropanoid ferulic acid, despite unaltered pool sizes of amino acid precursors ( $\mathrm{Li}$ et al., 2018a), suggesting that phenolic compounds may also be regulated by other secondary metabolite pathways.

Apart from glucosinolates and benzoxazinoids, volatile secondary metabolites such as terpenoids, green leaf volatiles and aromatic compounds can also regulate plant defenses (Baldwin et al., 2006; Godard et al., 2008; Erb, 2018; Bouwmeester et al., 2019). Many of these volatiles are released upon herbivore- or pathogen attack and are capable of directly inducing or priming hormonal defense signaling pathways and resistance. In maize for instance, mutants that are defective in their capacity to produce volatile indole are unable to prime their systemic tissues to rapidly release terpenes upon herbivore attack (Erb et al., 2015). Adding indole to the headspace of maize plants restores this priming phenotype (Erb et al., 2015). Rice plants also respond to indole through priming of early defense signaling elements such as the map kinase OsMPK3 (Ye et al., 2019). Transgenic plants that are deficient in OsMPK3 expression are no longer responsive to indole, suggesting that indole acts via the priming of early defense signaling (Ye et al., 2019). In Arabidopsis, geranylgeranyl reductase 1 mutants are defective in systemic acquired resistance against Pseudomonas syringae 
(Riedlmeier et al., 2017). Adding the pathogen induced volatiles $\alpha$ - and $\beta$-pinene to the headspace of the mutant restores resistance, with the response depending on intact salicylic acid signaling and the AZELAIC ACID INDUCED (AZI1) gene (Riedlmeier et al., 2017). The precise role of other volatile secondary metabolites that can regulate defenses at physiological concentrations, including homoterpenes (Arimura et al., 2000) and green leaf volatiles (Ameye et al., 2018) has not yet been explored using genetic approaches, but their activity has been demonstrated clearly through chemical complementation (Arimura et al., 2000; Engelberth et al., 2004; Frost et al., 2008; Meents et al., 2019). Further support for the potential regulatory role of defense volatiles comes from LOX2 silenced Nicotiana attenuata plants, which are deficient in the production of herbivory-induced green leaf volatiles. In contrast to the other systems where volatiles induce defense, the LOX2 mutants lead to stronger expression of defense-related genes in neighbors than wild type plants, suggesting that volatiles can also suppress defenses (Paschold et al., 2006).

In summary, at least five classes of secondary metabolites (glucosinolates, benzoxazinoids, terpenes, aromatics and green leaf volatiles) are now confirmed to act as potential regulators of in planta defense. It is exciting to speculate that these cases may just be the tip of the Iceberg, and that many other secondary metabolites may play similar regulatory roles. An important gap of knowledge is the mechanism by which secondary metabolites regulate defenses. As many of the secondary metabolites are chemically reactive (Farmer and Davoine, 2007; Hadacek et al., 2010), it is possible that they act indirectly by depleting detoxification enzymes, thus triggering the accumulation of known signaling molecules such as reactive oxygen species (ROS) (Khokon et al., 2011). However, as discussed below, secondary metabolites may also have hormone-like properties by binding to specific receptor proteins (Katz et al., 2015). More work on the targets of secondary metabolites in planta is clearly warranted and would help to clarify the ecological and evolutionary context of their capacity to regulate defenses.

Secondary metabolites as regulators of growth and development

Plants regulate their growth dynamically and often reduce their investment into growth and development upon herbivore- or pathogen attack. This reduction in growth is thought to be largely due to the reconfiguration of a plant's signaling network rather than a lack of resources (Kliebenstein, 2016; Machado et al., 2017; Guo et al., 2018). Strikingly, plant secondary metabolites and their breakdown products are being (re)discovered as plant growth modulators, thus adding another layer of regulation to growth-defense patterns. Again, glucosinolates provide a mechanistic example of how secondary metabolites can modulate growth. When applied to the roots of Arabidopsis and many other plant species, the aliphatic 3-hydroxypropylglucosinolate inhibits root meristematic growth at physiological concentrations via an intact Target of Rapamycin (TOR) pathway (Malinovsky et al., 2017). The exact molecular interaction partner of 3hydroxypropylglucosinolate remains unknown. Studies on the indole glucosinolate breakdown product indole-3-carbinol have identified an unexpected target protein. Indole-3-carbinol accumulates upon wounding in Arabidopsis and rapidly reduces root growth upon exogenous application. In vitro, indole-3-carbinol interferes with the interaction between auxin and its receptor TIR 1 by binding at an allosteric site (Katz et al., 2015). As the indolic glucosinolate catabolite likely binds directly to TIR1 (Katz et 
al., 2015), one may argue that TIR1 acts as an indolic glucosinolate receptor that mediates the regulation of growth by a plant secondary metabolite. Another link to auxin signaling was found with a structurally unrelated aliphatic glucosinolate. This was found by the initial observation that the auxin-sensitive repressors IAA5/6/19 strongly regulate 4-methylsulfinyl (4-MSO) glucosinolate levels in dehydrated Arabidopsis plants (Salehin et al., 2019). laa5,6,19 mutants fail to close their stomata upon drought stress, a phenotype which can be reverted by adding 4-MSO (Salehin et al., 2019). Together with the finding that glucosinolate biosynthesis and activation mutants are less tolerant to drought (Salehin et al., 2019), and that glucosinolate breakdown products can trigger stomatal closure in Arabidopsis and Vicia faba (Khokon et al., 2011; Hossain et al., 2013), these results provide evidence that aliphatic glucosinolates are involved in stomatal regulation. Interestingly, glucosinolate-mediated stomatal regulation requires a functional reactive oxygen species (ROS) receptor kinase (GHR1) (Salehin et al., 2019). Given that the myrosinase TGG1 accumulates in guard cells and is required for stomatal regulation (Zhao et al., 2008), and that glucosinolate breakdown products can regulate stomatal closure through ROS production (Khokon et al., 2011), it is conceivable that ROS link endogenous glucosinolates to stomatal regulation (Khokon et al., 2011).

Apart from growth and stomatal opening, glucosinolates may also regulate the circadian clock and flowering time. Natural presence/absence variation in the 2oxoglutarate-dependent dioxygenase AOP2, which converts methylsulfinylalkyl glucosinolates into alkenyl glucosinolates, is linked to variation in the expression of the major flowering gene FLC and to variation in flowering time (Kliebenstein et al., 2001; Atwell et al., 2010). Introducing a functional AOP2 into Col-0 (a natural AOP2 knockout) confirmed the flowering time effect, identified a shift in the expression of circadian genes and showed a one hour decrease in clock periodicity (Kerwin et al., 2011). Abolishing glucosinolate production using Myb transcription factor mutants lead to the same periodicity shift suggesting that the effect may be linked to the presence of the 4-MSO glucosinolate in WT Col-0 (Kerwin et al., 2011). The effect of the AOP locus on flowering time depends on the genetic background (Jensen et al., 2015), supporting the hypothesis that secondary metabolites are integrated into a complex and variable regulatory network. How aliphatic glucosinolates directly regulate gene expression networks and developmental phenotypes such as flowering time remains to be tested (Burow and Halkier, 2017).

The current data suggests that glucosinolates can influence growth by multiple different mechanisms, including TOR-regulation, auxin-regulation, auxin-independent transcriptional regulation and auxin-mediated ROS accumulation (Katz et al., 2015; Kim et al., 2015; Malinovsky et al., 2017; Salehin et al., 2019). This diversity, paired with the substantial variation in glucosinolate biosynthesis within species, creates a wealth of metabolic networks and phenotypes which can be acted upon by natural selection. It is tempting to speculate that this diversity is a reflection of the highly diverse habitats and environments that a single species can inhabit and may provide adaptive potential beyond conserved hormonal pathways.

288 In addition to glucosinolates, flavonoids are implicated in regulating growth, 289 development and plant environmental responses. Exogenously applied flavonoids 290 have long been known to modulate auxin transport (Stenlid, 1976). Evidence that 
flavonoids may also act as endogenous growth regulators came from an Arabidopsis chalcone synthase mutant, transparent testa (tt4). tt4 plants show growth alterations that are characteristic of disturbed auxin localization, including reduced root growth and gravitropism (Brown et al., 2001). The mutant also displays increased auxin transport (Murphy et al., 2000), which can be reversed by adding the flavonoid precursor naringenin (Brown et al., 2001). Further mechanistic studies suggest that flavonoids modulate auxin transport through several mechanisms, including interactions with auxin transporters and transport regulating proteins (Peer and Murphy, 2007; Santelia et al., 2008). Arabidopsis roots grow away from light, and flavonoids accumulate in light-exposed sides of Arabidopsis roots (Silva-Navas et al., 2016). A recent study found that the $t t 4$ mutant show reduced light avoidance, which was linked to reduced auxin polar transport and reduced ROS accumulation, both of which can regulate cell division and elongation (Gayomba et al., 2010; Silva-Navas et al., 2016). Flavonoid biosynthesis evolved in early land plants and likely preceded the emergence of polar auxin transport (Peer and Murphy, 2007). It is thus conceivable that flavonoids were integrated into hormonal regulation early on and thus represent an example of an evolutionarily integrated metabolic network between secondary metabolites and plant hormones.

Other secondary metabolites may also regulate plant development. In $N$. attenuata, silencing a malonyltransferase that malonylates 17-Hydroxygeranylinalool diterpene glycosides reduces floral style cell size and length (Li et al., 2018b). Knocking down diterpene glycoside production by silencing a geranylgeranyl diphosphate synthase leads to the disappearance of the effect of the malonyltransferase, suggesting that specific diterpene hexose decoration patterns are responsible for the flower phenotype (Li et al., 2018b). Furthermore, a labeling experiment in poplar recently uncovered that herbivore-attacked leaves can convert benzyl cyanide, a herbivore-induced volatile, to the auxin phenylacetic acid (Günther et al., 2018), thus providing a potential link between the catabolism of volatile secondary metabolites and the regulation of plant growth and development.

320 The examples above show how secondary metabolites can modulate growth and 321 development through a variety of mechanisms, some of which are barely distinguishable from mechanisms normally assigned to plant hormones (Figure 2). While some of these secondary metabolite regulators are ancient and highly conserved (e.g. flavonoids), others evolved more recently (e.g. glucosinolates and benzoxazinoids) and are restricted to specific plant families. Plants thus have both a conserved and a unique, variable and flexible repertoire of regulators at their disposition to adjust growth and development, which likely contributes to their potential to colonize variable and challenging habitats. 


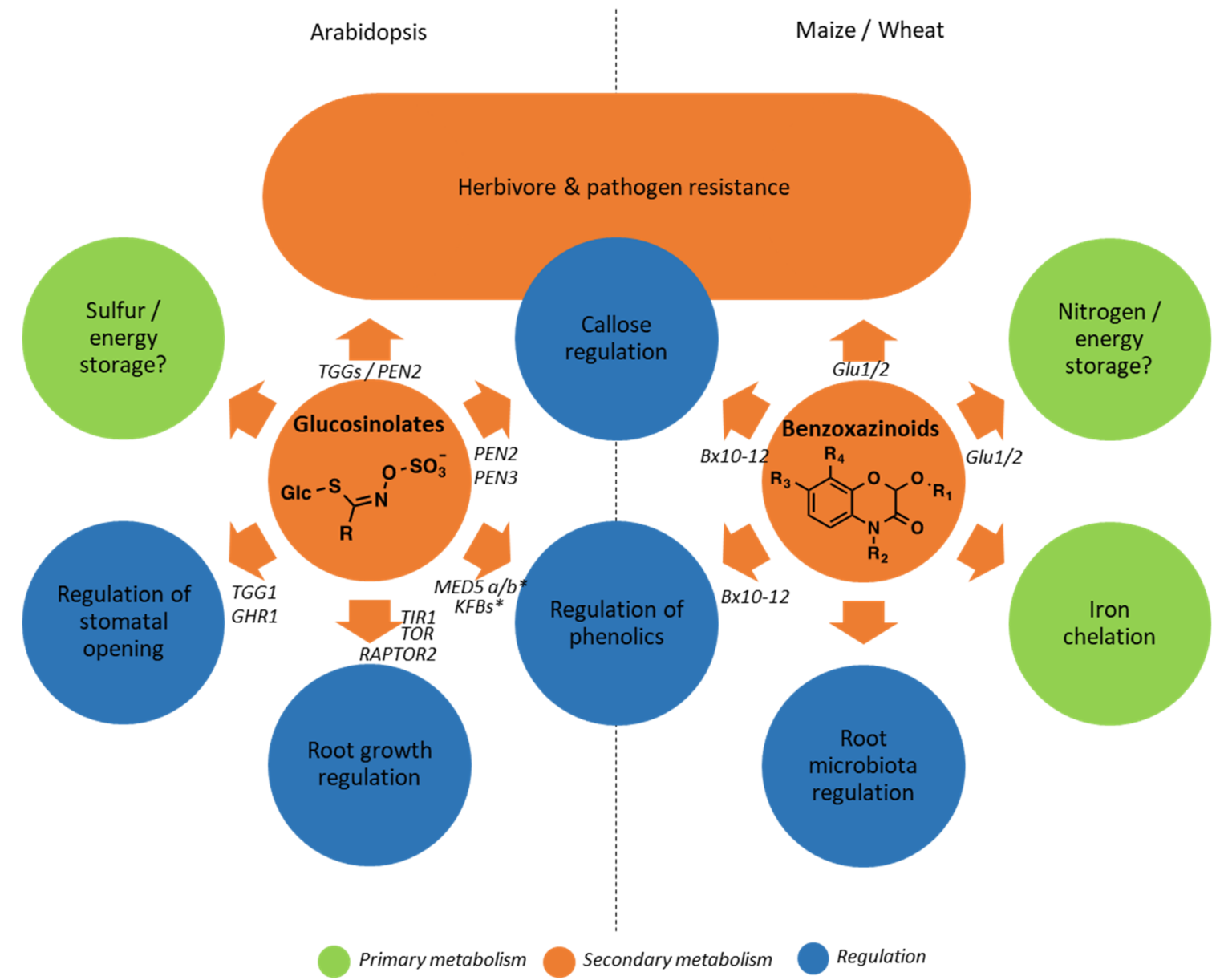

Figure 2. Glucosinolates and benzoxazinoids as examples of secondary metabolites that blurr the functional trichotomy of plant metabolism. Different functions of glucosinolates in Arabidopsis and benzoxazinoids in maize and wheat are depicted. Genes that are known to be involved in the different functions are indicated. Note that a direct role of benzoxazinoids and glucosinolates as plant primary metabolites (nitrogen/sulfur and/or energy storage) has not been demonstrated experimentally. ${ }^{*} M E D s$ and $K F B s$ are likely regulated by aldoxime precursors of glucosinolates. For references, see text.

\section{Secondary metabolites as primary metabolites}

If secondary metabolites can regulate growth, development and defense, can they also function as primary metabolites? While primary metabolites are highly conserved, secondary metabolites evolve dynamically and are inherently variable in structure and production (Wink, 2008). This rapid evolution would seem to complicate their integration into the most fundamental workings of plant metabolism because it would require a rapid evolution of enzymes to connect these novel structures into the more conserved metabolic pathways. However, evidence for secondary metabolites that are not strictly essential, but nevertheless contribute to primary metabolism, is emerging. In Arabidopsis, plants with mutations in the flavonoid pathway upstream of the FLAVANONE-3-HYDROXYLASE $(\mathrm{F} 3 \mathrm{H})$ show a reduction in the respiratory cofactor ubiquinone (coenzyme Q) (Soubeyrand et al., 2018). Ubiquinone levels can be restored by adding dihydrokaempferol or kaempferol to the mutants. Labelling experiments demonstrate that the aromatic ring of kaempferol is integrated into ubiquinone, and heme-dependent peroxidases were identified as enzymes that are 
likely to us kaempferol to produce 4-hydroxybenzoate as a substrate for ubiquinone 352 (Soubeyrand et al., 2018).

353 The integration of flavonoids into primary metabolism is maybe not a surprise, as they represent one of the oldest and most highly conserved classes of secondary metabolism (albeit with substantial inter-specific variation in glycosylation patterns), whose evolution precedes the emergence of many innovations in plant primary metabolism such as $\mathrm{C}_{4}$ photosynthesis. Whether younger, more specialized secondary metabolites can act as primary metabolites is not well understood. This lack of knowledge is closely related to a limited understanding of the catabolism of secondary metabolites. Where do these compounds go when they are no longer needed? One would assume that re-integrating secondary metabolites into primary metabolism should be beneficial for plants (Neilson et al., 2013). Such a re-integration pathway has been proposed for cyanogenic glycosides (Selmar et al., 1988). It was suggested that, upon deglycosylation, $\mathrm{HCN}$ may be assimilated into asparagine via the formation of $\beta$-cyanoalanine (Selmar et al., 1988), and two Sorghum nitrilases are indeed capable of producing asparagine from $\beta$-cyanoalanine (Jenrich et al., 2007). An alternative pathway not involving the release of HCN was suggested in Sorghum. In this system, nitrilases are proposed to take the deglycosylated cyanogen and directly release ammonia and the corresponding acetate (Jenrich et al., 2007). Further support for the potential of cyanogenic glucosides as a primary metabolite store came from everexpression of a hydroxynitrile lyase which is involved $\mathrm{HCN}$ formation in cassava. These plants have decreased concentrations of cyanogenic glycosides and increased concentrations of total amino acids, suggesting that cyanogenic glycosides may be degraded and reintegrated into primary metabolism (Narayanan et al., 2011).

Detailed metabolic profiling of secondary metabolite mutants in combination with complementation and labelling experiments are required to identify additional secondary metabolites that serve as precursors of primary metabolites in the future. Alterations in primary metabolites are observed in various plants with altered secondary metabolism (Mayer et al., 2001; Huber et al., 2016; Machado et al., 2017), but often attributed to differences in available resources and precursor accumulation (Ishihara et al., 2007). Keeping an open mind about the capacity of plants to evolve integrated metabolic networks is warranted if we are to work towards a better comprehension of the prevalence and importance of secondary metabolites as precursors of primary metabolites.

\section{Secondary metabolites as siderophores}

An additional example that further blurs the distinction between primary and secondary metabolism is plant micronutrient uptake. Grasses excrete small-molecular weight compounds into the rhizosphere to chelate micronutrients such as iron and thus make them biologically available (Curie and Briat, 2003). Recent work suggests that secondary metabolites can also act as siderophores and are likely important for iron uptake in both herbs and grasses. Chemical removal of excreted phenolic acids from the nutrient solution of red clover was found to result in iron deficiency in red clover (Jin et al., 2007). Subsequently, an Arabidopsis Feruloyl-CoA 6'-Hydroxylase1 mutant, who is no longer able to produce and release coumarins, was found to suffer from iron deficiency under alkaline conditions (Schmid et al., 2014). Similarly, young maize 
benzoxazinoid mutants who do no longer produce and excrete benzoxazinoids were found to suffer from iron deficiency when growing in the presence of iron salts (Hu et al., 2018). Both benzoxazinoids and coumarins are able to chelate iron in vitro (Bigler et al., 1996; Mladenka et al., 2010). As these complexes are essential for plant growth and development by providing essential micronutrients, they should, according to definition, be classified as primary metabolites, thus providing another illustration of how secondary metabolites can turn into primary metabolites under given conditions.

\section{Adaptive explanations for metabolic integration of secondary metabolites}

405

406

407

408

409

410

411

412

413

414

415

416

There is now ample evidence for secondary metabolites that are regulators and precursors of primary metabolites. But why would plants evolve an integrated metabolism in which the same metabolite class has multiple functions that incorporate growth, development, defense and regulation? Plants have large, interconnected metabolic networks at their disposition. Natural selection acts on these metabolic networks, resulting in the evolution of network topologies that maximize fitness. Over evolutionary time, these topologies likely include dynamic transitions between secondary metabolites and hormones, for instance (Malinovsky et al., 2017; Sun et al., $2019 b)$. Overall, the functional integration of secondary metabolites at a given point in evolution is a likely consequence of the interaction between complex environments with highly connected plant metabolic networks. Below, we discuss potential benefits of metabolic integration of plant secondary metabolites that may have favored their use as regulators and primary metabolites.

\section{Plant secondary metabolites as reliable readouts of defense activation}

Plants control defense activation to save metabolic energy and avoid self-damage. Defense investment is typically titrated through feedback regulation, including both positive and negative feedback loops that are built into early defense signaling (Hu et al., 2015; Li et al., 2015) and hormonal networks (Gilardoni et al., 2011; Liu et al., 2019). A limitation of these feedback loops is that they do not provide direct information about the final level of defense activation, i.e. the production of defense metabolites per se. As herbivores and pathogens may interfere with the production of defense compounds at many levels, including the final steps of biosynthesis (Jones et al., 2019), integrating them directly into regulatory feedback loops may allow plants to more accurately monitor and adjust defense activation. Using secondary metabolites as defense activation readouts may also help plants to optimize synergies between different defenses and to compensate for accidental failures of specific defense pathways. The increasing number of examples showing that plant secondary metabolites regulate defenses (see section "Secondary metabolites as regulators of plant defense") hint at the existence of such systems in plants.

As many secondary metabolites are compartmentalized and/or stored in inactive forms, their decompartmentalization and/or activation likely also helps plants to recognize tissue damage and other forms of environmental stress. In this case, the metabolites would be used as damage-associated molecular patterns (DAMPs). Green-leaf volatiles (GLVs) are an example of secondary metabolites that are also DAMPs (Tanaka et al., 2014; Quintana-Rodriguez et al., 2018). Another potential example of secondary metabolites as DAMPs are the previously discussed links 
between indolic glucosinolates and DIMBOA regulation of callose upon pathogen attack. Interestingly in this case, the secondary metabolite/DAMPs are linked to endogenous responses to pathogen-associated molecular patterns, e.g. FLS2, (Clay et al., 2009) and stomatal closure upon drought stress (Salehin et al., 2019).

Given these considerations, secondary metabolites may be common readouts of defense activation and damage may have favored their evolution as defense regulators.

\section{Metabolic network specialization as a means to resist manipulation}

Herbivores, pathogens and viruses can interfere with defense hormone signaling and thereby manipulate plants for their own benefit (Kazan and Lyons, 2014; Stahl et al., 2018). The high degree of conservation in defense hormone signaling may in fact favor the evolution of biotic manipulation of plant signaling (Berens et al., 2017). For example, if an attacking organism evolves the ability to alter jasmonate signaling this may provide it a fitness benefit on a wide variety of host plants and may reduce the advantage for plants to evolve new inducible resistance mechanisms regulated by these hormones. One possibility to solve this problem would be to use less conserved metabolites as defense regulators. If a plant had the ability to use these metabolites, it would be less likely to fall prey to host switching by hormone-manipulating enemies. The evolution of (specialized) secondary metabolites into regulatory networks may thus be promoted through the evolution of manipulation strategies in plant enemies. Clear examples supporting this hypothesis are currently lacking. Interestingly, an opposite pattern has been found for the tomato leaf spot fungus, which uses a hydrolase to detoxify steroidal glycoalkaloids and benefits from the defensesuppressing properties of the resulting breakdown products (Bouarab et al., 2002). This illustrates that specialized plant enemies may also misuse the regulatory properties of secondary metabolites of their host plants.

\section{Multifunctionality as a cost-saving strategy}

467 Producing secondary metabolites has energetic and metabolic costs. These costs are not always evident (Züst et al., 2011; Machado et al., 2017), and may mostly occur under specific environmental conditions such as strong competition and nutrient limitation (Cipollini et al., 2018-). Plants likely manage costs of secondary metabolite production through the regulation of biosynthesis, but controlled recycling of the resulting compounds would enhance the plants ability to recoup costs in challenging environments (Neilson et al., 2013). Secondary metabolites that are induced upon environmental stress could for instance be recycled back into primary metabolism once the stress subsides. One way of testing this hypothesis is to manipulate secondary metabolite recycling by targeting enzymes involved in their degradation, such as glucosidases (Morant et al., 2008) or nitrilases (Jenrich et al., 2007). Using this approach, a link between the degradation of cyanogenic glycosides and plant protein supply was uncovered (Narayanan et al., 2011), supporting the hypothesis that reintegration of secondary compounds into primary metabolism may be advantageous for the plant. A caveat of this approach is that it remains difficult to disentangle a direct contribution of the generated catabolites to primary metabolism from their potential regulatory roles. A more detailed understanding of secondary metabolite signaling and 
catabolism would help to explore the role of secondary metabolite reintegration as a cost-saving strategy.

Another way to minimize costs is to utilize the same secondary compound for multiple purposes (Neilson et al., 2013). As many secondary compounds are chemically reactive, they need to be managed by the plant through (potentially costly) storage, inactivation and/or resistance mechanisms, including specialized cells, ducts and glands (Sirikantaramas et al., 2008). By employing the same compound class for multiple purposes, plants may spread these fixed costs across more fitness components and increase their competitiveness. While the cost-saving aspects of multifunctionality are difficult to quantify, multifunctionality seems to be a widespread property of secondary metabolites, as discussed above, and it is difficult for this multifunctionality to evolve without benefit.

Ecological consequences of the metabolic integration of secondary metabolites

The separation of small molecular weight compounds into primary metabolites, secondary metabolites and hormones has shaped our ecological and evolutionary thinking in plant-environment interactions. If we abolish this view in favor of a more integrated perspective (i.e. where secondary metabolites can have regulatory roles and can provide precursors for primary metabolites), we can derive new hypotheses on plant defense patterns and plant-herbivore interactions. These hypotheses are likely to improve our understanding of the ecological roles of plant secondary metabolites in the future.

\section{Ontogenetic patterns of secondary metabolite production}

507

508

509

Many secondary metabolites show distinct ontogenetic accumulation patterns, with concentrations varying over time and between tissues. Ecological theory explains this within-plant variation using resource constraints, allocation costs and variation in herbivore pressure (McKey, 1974; van Dam, 2009; Meldau et al., 2012; Schuman and Baldwin, 2016; Barton and Boege, 2017). The above theories are all based on costs and benefit relationship, with the benefit typically being limited to herbivore resistance. Given the blurred trichotomy of plant secondary metabolism, the ecological balance sheet may be improved by taking into account multifunctionality (Barton and Boege, 2017). A drop in secondary metabolite levels, as is often observed a few weeks after germination or at the onset of flowering for instance (Meldau et al., 2012; Barton and Boege, 2017) may reflect an increased need of primary metabolites and nutrients rather than a drop in herbivore pressure. Similarly, strong expression of secondary metabolites in roots may not only be the result of high tissue value and a high risk of root herbivore attack, but may simply reflect additional functions of the compounds such as micronutrient uptake and microbial conditioning (Stringlis et al., 2018; Hu et al., 2018a; Hu et al., 2018b). Our understanding of ontogenetic allocation patterns of secondary metabolites may thus improve if we take their full metabolic integration and potential multifunctionality into account and do not limit their considered benefits to herbivore resistance.

Defense metabolites in plant-herbivore interactions 
The functional trichotomy used to define plant metabolites has also shaped our understanding of how these metabolites influence plant-herbivores interactions. Herbivores are assumed to forage for primary metabolites while trying to avoid the negative effects of secondary metabolites through behavioral and metabolic adaptations (Behmer, 2009) (Stahl et al., 2018). If we accept that secondary metabolites can also be regulators and precursors of primary metabolites, then it becomes conceivable that they may have similar roles in herbivores. The root feeding larvae of the western corn rootworm for instance forage for iron-benzoxazinoid complexes to acquire iron and improve their growth, thus effectively using a plant secondary metabolite as a primary metabolite (Hu et al., 2018). Several other herbivores also gain more weight in the presence of plant secondary metabolites (Meldau et al., 2009; Richards et al., 2012; Marti et al., 2013; Veyrat et al., 2016; Wetzel et al., 2016), and it is conceivable that some of these effects may be due to the capacity of the herbivores to metabolize these compounds. Recent examples also hint at the possibility that plant secondary metabolites may have hormonal functions in herbivores. In rice, knocking down CYP71A1 a gene responsible for the production of serotonin, a monoamine neurotransmitter, reduces the performance of the rice brown planthopper. Adding serotonin to artificial diet enhances its performance (Lu et al., 2018), suggesting that the herbivore may benefit from the hormonal properties of this plant metabolite. Plants may also benefit from producing secondary metabolites that act as (de)-regulators of herbivore physiology. Spinach for instance produces the molting hormone 20-hydroxyecdysone (Bakrim et al., 2008), which can interfere with caterpillar development (Kubo et al., 1983).

Box 1. Multifunctionality of plant secondary metabolites shapes the interaction between maize and the western corn rootworm- a case study. Young maize plants produce high amounts of benzoxazinoid secondary metabolites. Benzoxazinoids are used by the plant for multiple purposes, including direct resistance against herbivores (Glauser et al., 2011; Maag et al., 2016), the regulation of callose deposition as a defense against aphids (Ahmad et al., 2011; Meihls et al., 2013), and iron uptake through their capacity to chelate iron in the rhizosphere (Hu et al., 2018). Recent work shows that the western corn rootworm, a highly specialized maize pest, phenocopied these functions and is able to use benzoxazinoids for multiple purposes as well. The larvae of the herbivore use benzoxazinoids as foraging cues in the rhizosphere (Robert et al., 2012), they are able to extract iron from benzoxazinoidiron complexes to maximize their own growth (Hu et al., 2018), and they are able to store benzoxazinoids to resist their own enemies- entomopathogenic nematodes (Robert et al., 2017). Strikingly, both the plant and the herbivore have evolved to modify the structure, localization and stress-induced modification of benzoxazinoids to fit these different functions (Ahmad et al., 2011; Maag et al., 2016; Robert et al., 2017). This example illustrates how a detailed understanding of the functional integration of plant secondary metabolites can help to unravel the chemical underpinning of plant-herbivore interactions.

In general terms, a plant's metabolism is shaped by a dynamic landscape of environmental selection pressure; conversely, the metabolic network of herbivores is shaped by the functional and chemical potential of plant metabolites within the herbivore's own selection landscape; one can thus expect, that, similar to what Rhoades postulated for plants (Rhoades, 1977), any chemical system taken up by a herbivore must necessarily be integrated into its total metabolic scheme, and multiple functions of plant secondary metabolites are to be expected, some of which likely mirror their multiple functions in plants (Figure 3). Specialist herbivores are known to

574 sequester defenses to protect themselves against herbivore natural enemies (Nishida, 
2002; Opitz and Müller, 2009), in analogy to the use of these chemicals as defense regulators and resistance factors in plants (Figure 3). Cabbage aphids are an illustrative example in this context, as they can activate glucosinolates by producing their own myrosinases (Bridges et al., 2002; Kazana et al., 2007). This allows them to use glucosinolates as two-component defense system against predators (Kazana et al., 2007). As glucosinolate breakdown products (isothiocyanates) also increase aphid responses to alarm pheromones (Dawson et al., 1987), it was proposed that aphidreleased isothiocyanates may also act as danger-signals (Bridges et al., 2002). Another example where herbivores use secondary metabolites for several purposes that mirror their multiple uses by plants are again benzoxazinoids, which are used as defense metabolites and siderophores by a specialist root herbivore in maize (Box 1). Apart from mirroring plant functions, adapted herbivores can also use plant secondary metabolites for herbivore-specific functions. C yanogenic glycosides for instance can be used by specialized lepidoptera as defenses and nuptial gifts (Zagrobelny et al., 2018), and glucosinolates are part of the pheromone blend of flea beetles (Beran et al., 2016).

These examples illustrate that, as in plants, secondary metabolites can act as defenses, regulators and precursors of primary metabolites in herbivores. Furthermore, the multi-functionality of plant secondary metabolites for plants is reflected the multi-functional misuse of these compounds by specialized plant-feeders (Fig. 3). Whether similar phenomena can also be observed in natural enemies of herbivores, thus also shaping tritrophic interactions, is an exciting open question (Box 2).

Box 2. Potential novel roles of plant secondary metabolites in tritrophic interactions. Beyond plants and herbivores, the multi-functionality of plant secondary metabolites may also extend to the third trophic level. The current view on this topic is that i) plant primary metabolites influence tritrophic interactions by directly or indirectly feeding natural enemies of herbivores (Hunter, 2003; Sarfraz et al., 2009; Ugine et al., 2019), ii) volatile secondary metabolites can serve as foraging cues (Aartsma et al., 2017; Turlings and Erb, 2018), and iii) non-volatile secondary metabolites can reduce herbivore host quality and thereby negatively affect natural enemies of herbivores, in particular when they are sequestered by specialized herbivores (Nishida, 2002; Opitz and Müller, 2009). To what extent natural enemies of herbivores may use plant secondary metabolites as primary metabolites for their own nutrition or as hormone-like regulators is currently unknown. Natural enemies of herbivores can metabolize secondary metabolites (Sloggett and Davis, 2010; Robert et al., 2017; Sun et al., 2019a), and can evolve resistance towards their toxic effects (Fink and Brower, 1981; Rafter et al., 2017; Zhang et al., 2019). Understanding if and how plant secondary metabolites are integrated into the metabolism of herbivore natural enemies represents an important current frontier in chemical ecology which can benefit from current insights into the blurred functional trichotomy of plant metabolism.

In summary, the field of plant-herbivore interactions is likely to benefit from abandoning functional preconceptions of plant secondary metabolites and to focus on a better understanding of the metabolic integration of plants and insects through untinged glasses. Comparative metabolomics of plant and herbivore tissues (Jansen et al., 2009) and parallel genome-wide screens of plants and herbivores (Nallu et al., 2018) are promising approaches to assess plant-herbivore interaction and to identify metabolite functions and effects in herbivores without prior functional assumptions. 


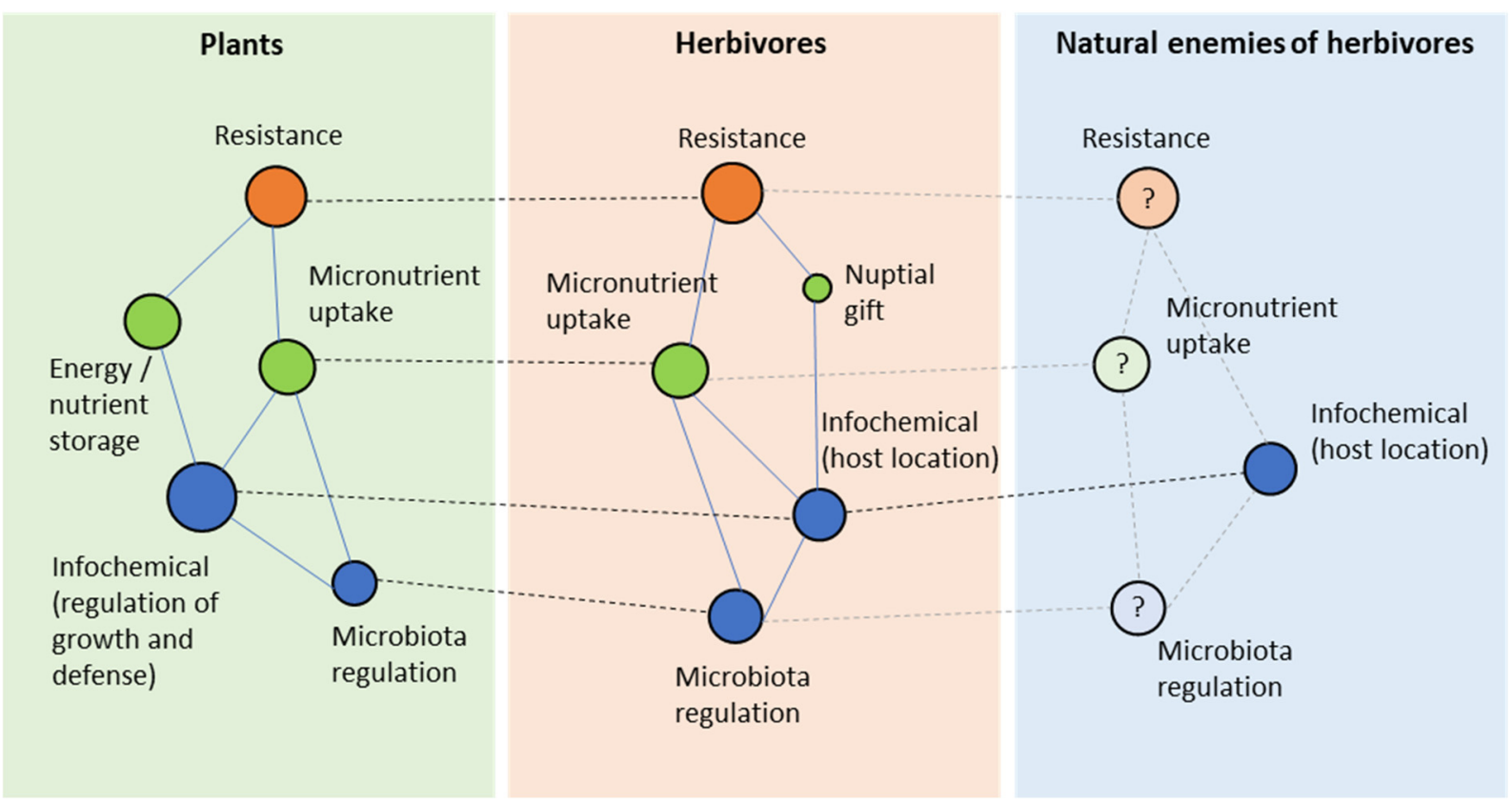

Figure 3. Functional integration of plant secondary metabolites shapes plant-herbivore and tritrophic interactions. Schematic representation of how different functions of secondary metabolites are used by plants, herbivores and natural enemies of herbivores. Plants use secondary metabolites for multiple purposes, including resistance, regulation and primary metabolism (see Figure 2). Recent work suggests that this multifunctionality is mirrored in adapted herbivores, which also employ secondary metabolites for multiple purposes, including similar and novel functions. Little is known about how adapted natural enemies use secondary metabolites, but multifunctional integration across three trophic levels is likely (Box 2). Circles represent hypothetical individual secondary metabolites (for color code, refer to Figs. 1 and 2). Solid lines indicate metabolic connections within an organism. Dashed lines indicate similar functions of the same compounds in different organisms.

\section{Conclusions}

632 The functional separation of plant-derived small molecular weight organic compounds into primary metabolites, secondary metabolites and hormones has proven to be a useful approximation over the last decades. However, recent work has shown that several classes of plant secondary metabolites are highly integrated into plant metabolism and can serve as both regulators and primary metabolites. Thus, it is likely that most secondary metabolites have additional functions for plants. Taking into account these additional can refine key concepts in plant-environment interactions and improve our understanding of the chemical ecology of plants and their enemies.

641 We would like to thank Christelle A.M. Robert, Clint Chapple and the twitter community 642 for helpful comments on an earlier version of this manuscript and Pierre Mateo for 643 drawing chemical structures. 
Aartsma Y, Bianchi FJJA, van der Werf W, Poelman EH, Dicke M (2017) Herbivore-induced plant volatiles and tritrophic interactions across spatial scales. New Phytol 216: 1054-1063.

Ahmad S, Veyrat N, Gordon-Weeks R, Zhang Y, Martin J, Smart L, Glauser G, Erb M, Flors V, Frey M, Ton J (2011) Benzoxazinoid metabolites regulate innate immunity against aphids and fungi in maize. Plant Physiol 157: 317-327.

Ameye M, Allmann S, Verwaeren J, Smagghe G, Haesaert G, Schuurink RC, Audenaert K (2018) Green leaf volatile production by plants: a meta-analysis. New Phytol 220: 666-683.

Arimura G, Ozawa R, Shimoda T, Nishioka T, Boland W, Takabayashi J (2000)

655 Herbivory-induced volatiles elicit defence genes in lima bean leaves. Nature 406: 512-515.

Atwell S, Huang YS, Vilhjálmsson BJ, Willems G, Horton M, Li Y, Meng D, Platt A, Tarone AM, Hu TT, Jiang R, Muliyati NW, Zhang X, Amer MA, Baxter I, Brachi B, Chory J, Dean C, Debieu M, Meaux J de, Ecker JR, Faure N, Kniskern JM, Jones JDG, Michael T, Nemri A, Roux F, Salt DE, Tang C, Todesco M, Traw MB, Weigel D, Marjoram P, Borevitz JO, Bergelson J, Nordborg M (2010) Genome-wide association study of 107 phenotypes in Arabidopsis thaliana inbred lines. Nature 465: 627-631.

Awmack CS, Leather SR (2002) Host plant quality and fecundity in herbivorous insects. Annu Rev Entomol 47: 817-844.

Bakrim A, Maria A, Sayah F, Lafont R, Takvorian N (2008) Ecdysteroids in spinach (Spinacia oleracea L.): biosynthesis, transport and regulation of levels. Plant Physiol Biochem 46: 844-854.

Baldwin IT, Halitschke R, Paschold A, Dahl CC von, Preston CA (2006) Volatile signaling in plant-plant interactions: "talking trees" in the genomics era. Science 311: 812-815.

Baldwin IT, Schultz JC (1983) Rapid changes in tree leaf chemistry induced by damage: evidence for communication between plants. Science 221: 277-279.

674

675

Barton KE, Boege K (2017) Future directions in the ontogeny of plant defence: understanding the evolutionary causes and consequences. Ecol Lett 20: 403-411.

Behmer ST (2009) Insect herbivore nutrient regulation. Annu Rev Entomol 54: 165187.

Beran F, Jiménez-Alemán GH, Lin M-y, Hsu Y-C, Mewis I, Srinivasan R, Ulrichs C, Boland W, Hansson BS, Reinecke A (2016) The Aggregation Pheromone of Phyllotreta striolata (Coleoptera: Chrysomelidae) Revisited. J Chem Ecol 42: 748755.

Berenbaum MR, Zangerl AR (2008) Facing the future of plant-insect interaction research: le retour à la "raison d'être". Plant Physiol 146: 804-811. 
Berens ML, Berry HM, Mine A, Argueso CT, Tsuda K (2017) Evolution of Hormone Signaling Networks in Plant Defense. Annu Rev Phytopathol 55: 401-425.

686

687

688

689

690

691

692

693

694

695

696

697

698

699

700

701

702

703

704

705

706

707

708

709

710

711

712

713

714

715

716

Bigler L, Baumeler A, Werner C, Hesse M (1996) Detection of Noncovalent Complexes of Hydroxamic-Acid Derivatives by means of electrospray mass spectrometry. Helv Chim Acta 79: 1701-1709.

Bouarab K, Melton R, Peart J, Baulcombe D, Osbourn A (2002) A saponindetoxifying enzyme mediates suppression of plant defences. Nature 418: 889892.

Bouwmeester H, Schuurink RC, Bleeker PM, Schiestl F (2019) The role of volatiles in plant communication. Plant J 100: 892-907.

Bridges M, Jones AME, Bones AM, Hodgson C, Cole R, Bartlet E, Wallsgrove R, Karapapa VK, Watts N, Rossiter JT (2002) Spatial organization of the glucosinolate-myrosinase system in brassica specialist aphids is similar to that of the host plant. Proc Biol Sci 269: 187-191.

Brown DE, Rashotte AM, Murphy AS, Normanly J, Tague BW, Peer WA, Taiz L, Muday GK (2001) Flavonoids Act as Negative Regulators of Auxin Transport in Vivo in Arabidopsis1. Plant Physiol 126: 524-535.

Burow M, Atwell S, Francisco M, Kerwin RE, Halkier BA, Kliebenstein DJ (2015) The Glucosinolate Biosynthetic Gene AOP2 Mediates Feed-back Regulation of Jasmonic Acid Signaling in Arabidopsis. Mol Plant 8: 1201-1212.

Burow M, Halkier BA (2017) How does a plant orchestrate defense in time and space? Using glucosinolates in Arabidopsis as case study. Curr Opin Plant Biol 38: $142-147$.

Cipollini D, Walters D, Voelckel C (2018-) Costs of Resistance in Plants: From Theory to Evidence. In JA Roberts, ed, Annual plant reviews. Wiley, [Place of publication not identified], pp. 263-307.

Clay NK, Adio AM, Denoux C, Jander G, Ausubel FM (2009) Glucosinolate metabolites required for an Arabidopsis innate immune response. Science 323: 95-101.

Curie C, Briat J-F (2003) Iron transport and signaling in plants. Annu Rev Plant Biol 54: 183-206.

Davies PJ (2004) Plant hormones. Biosythesis, signal transduction, action!, Ed. 3. Kluwer Academic, Dordrecht, Boston.

Dawson GW, Griffiths DC, Pickett JA, Wadhams LJ, Woodcock CM (1987) Plantderived synergists of alarm pheromone from turnip aphid,Lipaphis (Hyadaphis) erysimi (Homoptera, Aphididae). J Chem Ecol 13: 1663-1671.

Dolan WL, Dilkes BP, Stout JM, Bonawitz ND, Chapple C (2017) Mediator Complex Subunits MED2, MED5, MED16, and MED23 Genetically Interact in the Regulation of Phenylpropanoid Biosynthesis. Plant Cell 29: 3269-3285.

Ehrlich PR, Raven PH (1964) Butterflies and Plants: A Study in Coevolution. Evol 18: 586 . 
Engelberth J, Alborn HT, Schmelz EA, Tumlinson JH (2004) Airborne signals prime plants against insect herbivore attack. PNAS 101: 1781-1785.

Erb M (2018) Volatiles as inducers and suppressors of plant defense and immunityorigins, specificity, perception and signaling. Curr Opin Plant Biol 44: 117-121.

Erb M, Reymond P (2019) Molecular Interactions Between Plants and Insect Herbivores. Annu Rev Plant Biol 70: 527-557.

Erb M, Veyrat N, Robert CAM, Xu H, Frey M, Ton J, Turlings TCJ (2015) Indole is an essential herbivore-induced volatile priming signal in maize. Nat Commun 6: 6273.

Farmer EE, Davoine C (2007) Reactive electrophile species. Current opinion in plant biology 10: 380-386.

Fernie AR, Pichersky E (2015) Focus Issue on Metabolism: Metabolites, Metabolites Everywhere. Plant Physiol 169: 1421-1423.

Fink LS, Brower LP (1981) Birds can overcome the cardenolide defence of monarch butterflies in Mexico. Nature 291: 67-70.

Frost CJ, Mescher MC, Dervinis C, Davis JM, Carlson JE, Moraes CM de (2008) Priming defense genes and metabolites in hybrid poplar by the green leaf volatile cis-3-hexenyl acetate. New Phytol 180: 722-734.

Futuyma DJ, Agrawal AA (2009) Macroevolution and the biological diversity of plants and herbivores. PNAS 106: 18054-18061.

Gayomba SR, Watkins JM, Muday GK (2010) Flavonols Regulate Plant Growth and Development through Regulation of Auxin Transport and Cellular Redox Status. In C Santos-Buelga, MT Escribano-Bailon, V Lattanzio, eds, Recent advances in polyphenol research. Wiley-Blackwell, Chichester, West Sussex, Ames, lowa, pp. 143-170.

Gilardoni PA, Hettenhausen C, Baldwin IT, Bonaventure G (2011) Nicotiana attenuata LECTIN RECEPTOR KINASE1 suppresses the insect-mediated inhibition of induced defense responses during Manduca sexta herbivory. Plant Cell 23: 3512-3532.

Glauser G, Marti G, Villard N, Doyen GA, Wolfender J-L, Turlings TCJ, Erb M (2011) Induction and detoxification of maize 1,4-benzoxazin-3-ones by insect herbivores. Plant J 68: 901-911.

Godard K-A, White R, Bohlmann J (2008) Monoterpene-induced molecular responses in Arabidopsis thaliana. Phytochemistry 69: 1838-1849.

Günther J, Irmisch S, Lackus ND, Reichelt M, Gershenzon J, Köllner TG (2018) The nitrilase PtNIT1 catabolizes herbivore-induced nitriles in Populus trichocarpa. BMC plant biology 18: 251.

Guo Q, Major IT, Howe GA (2018) Resolution of growth-defense conflict: mechanistic insights from jasmonate signaling. Curr Opin Plant Biol 44: 72-81. 
Hadacek F, Bachmann G, Engelmeier D, Chobot V (2010) Hormesis and a Chemical Raison D'être for Secondary Plant Metabolites. Dose-response : a publication of International Hormesis Society 9: 79-116.

Hartmann T (2007) From waste products to ecochemicals: Fifty years research of plant secondary metabolism. Phytochemistry 68: 2831-2846.

Hasegawa K, Noguchi H, Iwagawa T, Hase T (1986) Phototropism in Hypocotyls of Radish : I. Isolation and Identification of Growth Inhibitors, cis- and transRaphanusanins and Raphanusamide, Involved in Phototropism of Radish Hypocotyls. Plant Physiol 81: 976-979.

Hemm MR, Ruegger MO, Chapple C (2003) The Arabidopsis ref2 mutant is defective in the gene encoding CYP83A1 and shows both phenylpropanoid and glucosinolate phenotypes. Plant Cell 15: 179-194.

Hossain MS, Ye W, Hossain MA, Okuma E, Uraji M, Nakamura Y, Mori IC, Murata Y (2013) Glucosinolate degradation products, isothiocyanates, nitriles, and thiocyanates, induce stomatal closure accompanied by peroxidase-mediated reactive oxygen species production in Arabidopsis thaliana. Biosci Biotechnol Biochem 77: 977-983.

Howe GA, Jander G (2008) Plant immunity to insect herbivores. Annu Rev Plant Biol 59: 41-66.

Hu L, Mateo P, Ye M, Zhang X, Berset JD, Handrick V, Radisch D, Grabe V, Köllner TG, Gershenzon J, Robert CAM, Erb M (2018) Plant iron acquisition strategy exploited by an insect herbivore. Science 361: 694-697.

Hu L, Ye M, Li R, Zhang T, Zhou G, Wang Q, Lu J, Lou Y (2015) The Rice Transcription Factor WRKY53 Suppresses Herbivore-Induced Defenses by Acting as a Negative Feedback Modulator of Mitogen-Activated Protein Kinase Activity. Plant Physiol 169: 2907-2921.

Huber M, Epping J, Schulze Gronover C, Fricke J, Aziz Z, Brillatz T, Swyers M, Köllner TG, Vogel H, Hammerbacher A, Triebwasser-Freese D, Robert CAM, Verhoeven K, Preite V, Gershenzon J, Erb M (2016) A Latex Metabolite Benefits Plant Fitness under Root Herbivore Attack. PLoS Biol 14: e1002332.

Hunter MD (2003) Effects of plant quality on the population ecology of parasitoids. Agric Forest Ent 5: 1-8.

Ishihara A, Matsuda F, Miyagawa H, Wakasa K (2007) Metabolomics for metabolically manipulated plants: effects of tryptophan overproduction. Metabolomics 3: 319-334.

Jander G (2018) Revisiting Plant-Herbivore Co-Evolution in the Molecular Biology Era. Annu Plant Rev: 361-384.

Jansen JJ, Allwood JW, Marsden-Edwards E, van der Putten WH, Goodacre R, van Dam NM (2009) Metabolomic analysis of the interaction between plants and herbivores. Metabolomics 5: 150-161. 
Jenrich R, Trompetter I, Bak S, Olsen CE, Møller BL, Piotrowski M (2007) Evolution of heteromeric nitrilase complexes in Poaceae with new functions in nitrile metabolism. PNAS 104: 18848-18853.

Jin CW, You GY, He YF, Tang C, Wu P, Zheng SJ (2007) Iron deficiency-induced secretion of phenolics facilitates the reutilization of root apoplastic iron in red clover. Plant Physiol 144: 278-285.

Jones AC, Seidl-Adams I, Engelberth J, Hunter CT, Alborn H, Tumlinson JH (2019) Herbivorous Caterpillars Can Utilize Three Mechanisms to Alter Green Leaf Volatile Emission. Environ Entomol 48: 419-425.

Katz E, Nisani S, Yadav BS, Woldemariam MG, Shai B, Obolski U, Ehrlich M, Shani E, Jander G, Chamovitz DA (2015) The glucosinolate breakdown product indole-3-carbinol acts as an auxin antagonist in roots of Arabidopsis thaliana. Plant J 82: 547-555.

Kazan K, Lyons R (2014) Intervention of Phytohormone Pathways by Pathogen Effectors. Plant Cell 26: 2285-2309.

Kazana E, Pope TW, Tibbles L, Bridges M, Pickett JA, Bones AM, Powell G, Rossiter JT (2007) The cabbage aphid: a walking mustard oil bomb. Proc Biol Sci 274: 2271-2277.

Kerwin RE, Jimenez-Gomez JM, Fulop D, Harmer SL, Maloof JN, Kliebenstein DJ (2011) Network quantitative trait loci mapping of circadian clock outputs identifies metabolic pathway-to-clock linkages in Arabidopsis. Plant Cell 23: 471485.

Khokon MAR, Jahan MS, Rahman T, Hossain MA, Muroyama D, Minami I, Munemasa S, Mori IC, Nakamura Y, Murata Y (2011) Allyl isothiocyanate (AITC) induces stomatal closure in Arabidopsis. Plant Cell Environ 34: 1900-1906.

Kim JI, Dolan WL, Anderson NA, Chapple C (2015) Indole Glucosinolate Biosynthesis Limits Phenylpropanoid Accumulation in Arabidopsis thaliana. Plant Cell 27: 1529-1546.

Kim JI, Zhang X, Pascuzzi PE, Liu C-J, Chapple C (2020) Glucosinolate and phenylpropanoid biosynthesis are linked by proteasome-dependent degradation of PAL. New Phytol 225: 154-168.

Kliebenstein DJ (2016) False idolatry of the mythical growth versus immunity tradeoff in molecular systems plant pathology. Phys Mol Plant Pathol 95: 55-59.

Kliebenstein DJ (2018) Plant nutrient acquisition entices herbivore. Science 361: 642-643.

Kliebenstein DJ, Lambrix VM, Reichelt M, Gershenzon J, Mitchell-Olds T (2001) Gene duplication in the diversification of secondary metabolism: tandem 2oxoglutarate-dependent dioxygenases control glucosinolate biosynthesis in Arabidopsis. Plant Cell 13: 681-693.

Kubo I, Klocke JA, Asano S (1983) Effects of ingested phytoecdysteroids on the growth and development of two Lepidopterous larvae. Journal of Insect Physiology 29: 307-316. 
Li B, Förster C, Robert CAM, Züst T, Hu L, Machado RAR, Berset J-D, Handrick V, Knauer T, Hensel G, Chen W, Kumlehn J, Yang P, Keller B, Gershenzon J, Jander G, Köllner TG, Erb M (2018a) Convergent evolution of a metabolic switch between aphid and caterpillar resistance in cereals. Sci Adv 4: eaat6797.

Li J, Schuman MC, Halitschke R, Li X, Guo H, Grabe V, Hammer A, Baldwin IT (2018b) The decoration of specialized metabolites influences stylar development. eLife 7.

Li R, Zhang J, Li J, Zhou G, Wang Q, Bian W, Erb M, Lou Y (2015) Prioritizing plant defence over growth through WRKY regulation facilitates infestation by nontarget herbivores. eLife 4: e04805.

Liu Y, Du M, Deng L, Shen J, Fang M, Chen Q, Lu Y, Wang Q, Li C, Zhai Q (2019) MYC2 Regulates the Termination of Jasmonate Signaling via an Autoregulatory Negative Feedback Loop. Plant Cell 31: 106-127.

Lu H-P, Luo T, Fu H-W, Wang L, Tan Y-Y, Huang J-Z, Wang Q, Ye G-Y, Gatehouse AMR, Lou Y-G, Shu Q-Y (2018) Resistance of rice to insect pests mediated by suppression of serotonin biosynthesis. Nat Plants 4: 338-344.

Maag D, Erb M, Köllner TG, Gershenzon J (2015) Defensive weapons and defense signals in plants: some metabolites serve both roles. Bioessays 37: 167-174.

Maag D, Köhler A, Robert CAM, Frey M, Wolfender J-L, Turlings TCJ, Glauser G, Erb M (2016) Highly localized and persistent induction of Bx1-dependent herbivore resistance factors in maize. Plant J 88: 976-991.

Machado RAR, Baldwin IT, Erb M (2017) Herbivory-induced jasmonates constrain plant sugar accumulation and growth by antagonizing gibberellin signaling and not by promoting secondary metabolite production. New Phytol 215: 803-812.

Malinovsky FG, Thomsen M-LF, Nintemann SJ, Jagd LM, Bourgine B, Burow M, Kliebenstein DJ (2017) An evolutionarily young defense metabolite influences the root growth of plants via the ancient TOR signaling pathway. eLife 6 .

Marti G, Erb M, Boccard J, Glauser G, Doyen GR, Villard N, Robert CAM, Turlings TCJ, Rudaz S, Wolfender J-L (2013) Metabolomics reveals herbivoreinduced metabolites of resistance and susceptibility in maize leaves and roots. Plant Cell Environ 36: 621-639.

Mayer MJ, Narbad A, Parr AJ, Parker ML, Walton NJ, Mellon FA, Michael AJ (2001) Rerouting the Plant Phenylpropanoid Pathway by Expression of a Novel Bacterial Enoyl-CoA Hydratase/Lyase Enzyme Function. Plant Cell 13: 16691682.

McKey D (1974) Adaptive Patterns in Alkaloid Physiology. Am Nat 108: 305-320.

Meents AK, Chen S-P, Reichelt M, Lu H-H, Bartram S, Yeh K-W, Mithöfer A (2019) Volatile DMNT systemically induces jasmonate-independent direct antiherbivore defense in leaves of sweet potato (Ipomoea batatas) plants. Sci Rep 9: 17431.

Meihls LN, Handrick V, Glauser G, Barbier H, Kaur H, Haribal MM, Lipka AE, Gershenzon J, Buckler ES, Erb M, Köllner TG, Jander G (2013) Natural 
variation in maize aphid resistance is associated with 2,4-dihydroxy-7-methoxy1,4-benzoxazin-3-one glucoside methyltransferase activity. Plant Cell 25: 23412355.

Meldau S, Erb M, Baldwin IT (2012) Defence on demand: mechanisms behind optimal defence patterns. Ann Bot 110: 1503-1514.

Meldau S, Wu J, Baldwin IT (2009) Silencing two herbivory-activated MAP kinases, SIPK and WIPK, does not increase Nicotiana attenuata's susceptibility to herbivores in the glasshouse and in nature. New Phytol 181: 161-173.

\section{Mladenka P, Macáková K, Zatloukalová L, Reháková Z, Singh BK, Prasad AK,} Parmar VS, Jahodár L, Hrdina R, Saso L (2010) In vitro interactions of coumarins with iron. Biochimie 92: 1108-1114.

Morant AV, Jørgensen K, Jørgensen C, Paquette SM, Sánchez-Pérez R, Møller BL, Bak S (2008) beta-Glucosidases as detonators of plant chemical defense. Phytochemistry 69: 1795-1813.

Murphy A, Peer WA, Taiz L (2000) Regulation of auxin transport by aminopeptidases and endogenous flavonoids. Planta 211: 315-324.

Nallu S, Hill JA, Don K, Sahagun C, Zhang W, Meslin C, Snell-Rood E, Clark NL, Morehouse NI, Bergelson J, Wheat CW, Kronforst MR (2018) The molecular genetic basis of herbivory between butterflies and their host plants. Nat Ecol Evol 2: 1418-1427.

Narayanan NN, Ihemere U, Ellery C, Sayre RT (2011) Overexpression of hydroxynitrile lyase in cassava roots elevates protein and free amino acids while reducing residual cyanogen levels. PLoS One 6: e21996.

Neilson EH, Goodger JQD, Woodrow IE, Møller BL (2013) Plant chemical defense: at what cost? Trends Plant Sci 18: 250-258.

Nishida R (2002) Sequestration of defensive substances from plants by Lepidoptera. Annu Rev Entomol 47: 57-92.

Opitz SEW, Müller C (2009) Plant chemistry and insect sequestration. Chemoecol 19: 117-154.

Paschold A, Halitschke R, Baldwin IT (2006) Using 'mute' plants to translate volatile signals. Plant J 45: 275-291.

Peer WA, Murphy AS (2007) Flavonoids and auxin transport: modulators or regulators? Trends Plant Sci 12: 556-563.

Pichersky E, Raguso RA (2018) Why do plants produce so many terpenoid compounds? New Phytol 220: 692-702.

Quintana-Rodriguez E, Duran-Flores D, Heil M, Camacho-Coronel X (2018) Damage-associated molecular patterns (DAMPs) as future plant vaccines that protect crops from pests. Sci Hort 237: 207-220.

Rafter JL, Gonda-King L, Niesen D, Seeram NP, Rigsby CM, Preisser EL (2017) Impact of Consuming 'Toxic' Monarch Caterpillars on Adult Chinese Mantid Mass Gain and Fecundity. Insects 8. 
Rhoades DF (1977) Integrated antiherbivore, antidesiccant and ultraviolet screening properties of creosotebush resin. Biochem Syst Ecol 5: 281-290.

931

932

933

934

935

936

937

938

939

940

941

942

943

944

945

946

947

948

949

950

951

952

953

954

955

956

957

958

959

960

961

962

963

964

965

966

967

968

969

970

Rhoades DF (1983) Responses of Alder and Willow to Attack by Tent Caterpillars and Webworms: Evidence for Pheromonal Sensitivity of Willows. In PA Hedin, ed, Plant resistance to insects, Vol 208. ACS, Washington, pp. 55-68.

Richards LA, Lampert EC, Bowers MD, Dodson CD, Smilanich AM, Dyer LA (2012) Synergistic effects of iridoid glycosides on the survival, development and immune response of a specialist caterpillar, Junonia coenia (Nymphalidae). J Chem Ecol 38: 1276-1284.

RiedImeier M, Ghirardo A, Wenig M, Knappe C, Koch K, Georgii E, Dey S, Parker JE, Schnitzler J-P, Vlot AC (2017) Monoterpenes Support Systemic Acquired Resistance within and between Plants. Plant Cell 29: 1440-1459.

Robert CAM, Veyrat N, Glauser G, Marti G, Doyen GR, Villard N, Gaillard MDP, Köllner TG, Giron D, Body M, Babst BA, Ferrieri RA, Turlings TCJ, Erb M (2012) A specialist root herbivore exploits defensive metabolites to locate nutritious tissues. Ecol Lett 15: 55-64.

Robert CAM, Zhang X, Machado RA, Schirmer S, Lori M, Mateo P, Erb M, Gershenzon J (2017) Sequestration and activation of plant toxins protect the western corn rootworm from enemies at multiple trophic levels. eLife 6 .

Salehin M, Li B, Tang M, Katz E, Song L, Ecker JR, Kliebenstein DJ, Estelle M (2019) Auxin-sensitive Aux/IAA proteins mediate drought tolerance in Arabidopsis by regulating glucosinolate levels. Nat Commun 10: 4021.

Santelia D, Henrichs S, Vincenzetti V, Sauer M, Bigler L, Klein M, Bailly A, Lee Y, Friml J, Geisler M, Martinoia E (2008) Flavonoids Redirect PIN-mediated Polar Auxin Fluxes during Root Gravitropic Responses 31218-31226.

Sarfraz M, Dosdall LM, Keddie BA (2009) Host plant nutritional quality affects the performance of the parasitoid Diadegma insulare. Biol Cont 51: 34-41.

Schmid NB, GiehI RFH, Döll S, Mock H-P, Strehmel N, Scheel D, Kong X, Hider RC, Wirén N von (2014) Feruloyl-CoA 6'-Hydroxylase1-dependent coumarins mediate iron acquisition from alkaline substrates in Arabidopsis. Plant Physiol 164: 160-172.

Schuman MC, Baldwin IT (2016) The Layers of Plant Responses to Insect Herbivores. Annu Rev Entomol 61: 373-394.

Selmar D, Lieberei R, Biehl B (1988) Mobilization and utilization of cyanogenic glycosides: the linustatin pathway. Plant Physiol 86: 711-716.

Silva-Navas J, Moreno-Risueno MA, Manzano C, Téllez-Robledo B, NavarroNeila S, Carrasco V, Pollmann S, Gallego FJ, Del Pozo JC (2016) Flavonols Mediate Root Phototropism and Growth through Regulation of Proliferation-toDifferentiation Transition. Plant Cell 28: 1372-1387.

Sirikantaramas S, Yamazaki M, Saito K (2008) Mechanisms of resistance to selfproduced toxic secondary metabolites in plants. Phytochem Rev 7: 467-477. 
Sloggett JJ, Davis AJ (2010) Eating chemically defended prey: alkaloid metabolism in an invasive ladybird predator of other ladybirds (Coleoptera: Coccinellidae). J Exp Biol 213: 237-241.

Soubeyrand E, Johnson TS, Latimer S, Block A, Kim J, Colquhoun TA, Butelli E, Martin C, Wilson MA, Basset GJ (2018) The Peroxidative Cleavage of Kaempferol Contributes to the Biosynthesis of the Benzenoid Moiety of Ubiquinone in Plants. Plant Cell 30: 2910-2921.

Stahl E, Hilfiker O, Reymond P (2018) Plant-arthropod interactions: who is the winner? Plant J 93: 703-728.

Stenlid G (1963) The Effects of Flavonoid Compounds on Oxidative Phosphorylation and on the Enzymatic Destruction of Indoleacetic Acid. Physiol Plant 16: 110-120.

Stenlid G (1976) Effects of Flavonoids on the Polar Transport of Auxins. Physiol Plant 38: 262-266.

Sun R, Jiang X, Reichelt M, Gershenzon J, Pandit SS, Giddings Vassão D (2019a) Tritrophic metabolism of plant chemical defenses and its effects on herbivore and predator performance. eLife 8.

Sun Y, Harpazi B, Wijerathna-Yapa A, Merilo E, Vries J de, Michaeli D, Gal M, Cuming AC, Kollist H, Mosquna A (2019b) A ligand-independent origin of abscisic acid perception. PNAS 116: 24892-24899.

Taiz L, Zeiger E, Møller IM, Murphy AS (2015) Plant physiology and development. Sinauer Associates, Sunderland, Massachusetts U.S.A.

Tanaka K, Choi J, Cao Y, Stacey G (2014) Extracellular ATP acts as a damageassociated molecular pattern (DAMP) signal in plants. Front Plant Sci $\mathbf{5}$.

Turlings TCJ, Erb M (2018) Tritrophic Interactions Mediated by Herbivore-Induced Plant Volatiles: Mechanisms, Ecological Relevance, and Application Potential. Annu Rev Entomol 63: 433-452.

Ugine TA, Krasnoff SB, Grebenok RJ, Behmer ST, Losey JE (2019) Prey nutrient content creates omnivores out of predators. Ecol Lett 22: 275-283.

van Dam NM (2009) Belowground Herbivory and Plant Defenses. Annu Rev Ecol Evol Syst 40: 373-391.

Veyrat N, Robert CAM, Turlings TCJ, Erb M (2016) Herbivore intoxication as a potential primary function of an inducible volatile plant signal. J Ecol 104: 591600.

Wetzel WC, Kharouba HM, Robinson M, Holyoak M, Karban R (2016) Variability in plant nutrients reduces insect herbivore performance. Nature 539: 425-427.

Wink M (2008) Plant Secondary Metabolism: Diversity, Function and its Evolution. Nat Prod Commun 3: $1934578 \times 0800300$.

Ye M, Glauser G, Lou Y, Erb M, Hu L (2019) Molecular Dissection of Early Defense Signaling Underlying Volatile-Mediated Defense Regulation and Herbivore Resistance in Rice. Plant Cell 31: 687-698. 
1011

1012

1013

1014

1015

1016

1017

1018

1019

1020

1021

1022

1023

1024

1025

1026

1027

1028

1029

Zagrobelny M, Castro ÉCP de, Møller BL, Bak S (2018) Cyanogenesis in Arthropods: From Chemical Warfare to Nuptial Gifts. Insects $\mathbf{9}$.

Zhang X, Gou M, Liu C-J (2013) Arabidopsis Kelch repeat F-box proteins regulate phenylpropanoid biosynthesis via controlling the turnover of phenylalanine ammonia-lyase. Plant Cell 25: 4994-5010.

Zhang X, van Doan C, Arce CCM, Hu L, Gruenig S, Parisod C, Hibbard BE, Hervé MR, Nielson C, Robert CAM, Machado RAR, Erb M (2019) Plant defense resistance in natural enemies of a specialist insect herbivore. PNAS 116: 2317423181.

Zhao Z, Zhang W, Stanley BA, Assmann SM (2008) Functional proteomics of Arabidopsis thaliana guard cells uncovers new stomatal signaling pathways. Plant Cell 20: 3210-3226.

Zhou S, Lou Y-R, Tzin V, Jander G (2015) Alteration of Plant Primary Metabolism in Response to Insect Herbivory. Plant Physiol 169: 1488-1498.

Zhou S, Richter A, Jander G (2018) Beyond Defense: Multiple Functions of Benzoxazinoids in Maize Metabolism. Plant Cell Physiol 59: 1528-1537.

Züst T, Joseph B, Shimizu KK, Kliebenstein DJ, Turnbull LA (2011) Using knockout mutants to reveal the growth costs of defensive traits. Proc Biol Sci 278: 2598-2603. 